\title{
The Effect of High School Program and University Study Length on Taiwanese EFL University Students' Motivational Identities and Learning Strategy Use
}

\author{
D. Ryan Berg * \\ Department of Applied Foreign Languages, TransWorld University \\ 1221 Zhennan Road, Douliu 64063, Taiwan \\ Tel: 886-988-082663 E-mail: AFL.Ryan@gmail.com \\ Yichen $\mathrm{Lu}$ \\ Department of Applied Foreign Languages, TransWorld University \\ 1221 Zhennan Road, Douliu 64063, Taiwan \\ Tel: 886-988-959281 E-mail: AFL.JaneLu@gmail.com
}

\begin{abstract}
Language learning strategies and motivational selves are two important factors that contribute to language learning success. Examining these variables and discovering what impacts them can help learners to understand their own motivation and strategy use and help teachers formulate better lesson plans and instruction. Besides being independent variables, they have also been shown to be related to one another. This study seeks to examine the impact of high school program and current year of study on Taiwanese university English majors' motivational selves and language learning strategy choices. Using the SILL and a Motivational Self Systems questionnaire, data was collected from 96 students across all four undergraduate years at a private Taiwanese university. The results show that there are correlations between motivational factors and some types of learning strategies. However, there were no significant differences among the sample according to either high school program or current year of study. It is suggested that other factors, such as geographical location of the students' homes or the economic level of the students' families may have an impact. Future research should continue to explore these phenomena.
\end{abstract}

Keywords: Language learning strategies, L2 motivation, Motivational self system, EFL students, SILL

DOI: $10.7176 / J L L L / 53-05$

\section{Introduction}

Motivation and learning strategies are two integral parts of both successful learning and successful learners, and both have been increasingly researched over the past forty years (e.g. Dörnyei \& Ushioda, 2011; Oxford, 2017). Examining these variables and discovering what impacts them can help learners to understand their own motivation and strategy use and help teachers formulate better lesson plans and instruction.

Motivation can greatly impact L2 learners' learning, strategy use, and autonomy. Motivation "is the process whereby goal-directed activities are instigated and sustained" (Schunk, Meece, \& Pintrich, 2014, p. 5); as such, it is driven by a learner's desire to learn and their beliefs as well as their inherent traits and positive effects from learning. Cohen (2010) noted that motivation was one of the key components that determine how efficiently language learners learn an L2. Similarly, a learner's use of learning strategies can greatly impact the speed at which they acquire a language.

Language learning strategies are "the special thoughts or behaviors that individuals use to help them comprehend, learn, or retain new information" (O’Malley \& Chamot, 1990, p. 1). While research into this area began with Rubin (1975) examining which strategies were used by successful language learners, the last several decades have produced an enormous amount of research that has contributed to our understanding of this area (see Cohen \& Macaro, 2007 for a synthesis of past research). Oxford (1990) stated that learners use sets of language learning strategies to aid their comprehension, storage, retrieval, and application of information when learning and using second or foreign languages. She noted that "learning strategies are behaviors or actions which learners use to make language learning more successful, self-directed and enjoyable" (p. 8). Thus, they help learners facilitate their learning and make learning more effective.

The purpose of this research is to examine a population of Taiwanese university English majors' ideal L2 selves, usage of language learning strategies, and whether their previous or current educational experience impacts those factors. Specifically, this study seeks to examine whether any relationship is present among the population's ideal L2 selves and language learning strategy use and whether these variables are affected by the high school program that the subjects attended or their current year of study in university.

Previous and current educational society are important factors because Taiwanese society has become 
increasingly M-shaped (Zhan \& Xue, 2008), giving rise to educational opportunity inequalities between urban and rural areas. Compounding this is the fact that there are three types of senior high schools in Taiwan: normal high schools, technical high schools, and comprehensive high schools, which house both a normal and technical school. A student attending a technical school cannot be expected to have the same quality of English education as a student attending a normal high school program. Investigating this issue should shed light on whether differing high school programs impact Taiwanese English majors' motivational selves and learning strategy usage.

\section{Literature Review}

This section will examine the previous literature on the L2 Motivational Self System and language learning strategies, both in general and as they relate to the current study.

\subsection{L2 Motivational Self System}

The L2 Motivational Self System (Dörnyei, 2005, 2009) is the most recent approach to L2 motivational research and can be seen as a synthesis of previous research (Gardner, 1985; Noels, Pelletier, Clément, \& Vallerand, 2000; Ushioda, 2002). While Gardner's (1985) socio-educational model dominated language learning motivation research for decades, the inadequacies of the integrative orientation began to be revealed when scholars started examining ESL and EFL contexts. In short, students in EFL contexts often have limited connections to native speakers and the L2 environment. As such, they may not have an integrative orientation or be able to define who the "owner" of English is (Dörnyei, 2009). In a globalized world, integrative orientation falls short and fails to describe learners studying World English; indeed, instrumental orientations may be more prevalent (Dörnyei, 1990; Warden \& Lin, 2000).

The L2 Motivational Self System (Dörnyei, 2005) has three main components: the Ideal L2 Self, the Oughtto L2 Self, and the L2 Learning Experience. While the Ideal L2 Self refers to the L2 speaker we would like to become, the Ought-to L2 Self refers "to the attributes that one believes one ought to possess (i.e., various duties, obligations, or responsibilities) in order to avoid possible negative outcomes" (Dörnyei, 2005, pp. 105-106) and the L2 Learning Experience "concerns situation-specific motives related to the immediate learning environment and experience" (p. 106).

With the notion of integrativeness exposed as unsatisfactory and inadequate for L2 learners of world English, the L2 Motivational Self System has been used in a great number of studies (see Dörnyei \& Ushioda, 2009, 2011). Taguchi, Magid, and Papi (2009), for example, examined thousands of Chinese, Japanese, and Iranian learners, and found that the Ideal L2 Self had more explanatory power than the Gardnerian concept of integrativeness and should thus replace it. Moreover, they found that the notion of instrumentality could be separated into two distinct types: one associated with the Ideal L2 Self, named Instrumentality-Promotion, and one associated with the Ought-to Self, named Instrumentality-Prevention. Overall, their model found a good fit with the data and was deemed to accurately describe Asian English learners of different cultural and educational backgrounds.

There have been relatively few studies utilizing the L2 Motivational Self System among English learners in Taiwan. Chu (2014) examined 185 3rd-year university students' Ideal L2 Selves and found a positive correlation between that and their International Posture (Yashima, 2002, 2002). Her results also showed that English learners in Taiwan tended to rely on their parents' expectations and preferences when choosing future goals and careers.

Lo (2015) and Ko (2015) both examined junior high school students. Lo's qualitative study examined their L2 Selves and International Posture, as well as that of their parents. She found that English learners did not have a perception of the ideal English self, but they did have a concept of their Ought-to Self, which was shaped by their parents' expectations. Ko examined the students L2 Motivational Self Systems across different regional contexts - urban and rural settings. She found differences among the groups and predictors for each group. For Taipei City learners, Ideal L2 Self and Instrumentality-Prevention were predictors, while Ought-to Self was a predictor variable for learners in Taidong.

\subsection{Language Learning Strategies}

Language learning strategies help learners become active, confident, and self-directed learners by enhancing their language learning and minimizing their weaknesses. They help learners to accomplish language tasks and solve problems encountered during the learning process (Cheng, 2015). Language learning strategies are used by learners at all levels, but many are unaware that they are using strategies at all (Ehrman \& Oxford, 1990). While early research on language learning strategies focused on what good language learners do (Naiman, Fröhlich, Stern, \& Todesco, 1996; Rubin, 1975), it is possible that unsuccessful learners misuse language learning strategies or do not know how to use them to facilitate language learning (Cohen, 2011). As such, it is important for researchers to examine students' strategy use so that teachers can more effectively teach learners those 
strategies which they may not be using or which may be beneficial to their learning.

With the immense amount of research into language learning strategies over the past several decades, several definitions have come about. In addition to the one provided by O'Malley and Chamot (1990) previously, we can also define them, much more specifically and methodically, as "thoughts and actions, consciously chosen and operationalized by language learners, to assist them in carrying out a multiplicity of tasks from the very onset of learning to the most advanced levels of target-language performance" (p. 7).

In addition to definitions, there have been many classifications of learning strategies. For the purposes of this study, we shall focus on those that draw from cognitive psychology, which Chamot, Barnhardt, El-Dinary, and Robbins (1996) noted "seemed best to capture the nature of learner strategies reported by students" (p. 179). These classification systems first distinguished between cognitive and metacognitive strategies as well as socialaffective strategies. In these schemes, metacognitive strategies are used for planning, monitoring, and evaluating learning, while cognitive strategies are used for elaborating on, grouping, inferencing from, and summarizing information, whereas social/affective strategies are used for questioning, cooperating, and self-talk during learning (Chamot et al., 1996).

This classification scheme was expanded by Oxford (1990), who classified strategies into direct and indirect strategies and separated social and affective strategies, while adding compensation and memory strategies. In this scheme, direct strategies, named so because they "directly involve the target language" (p. 37) include memory, cognitive, and compensation strategies. According to Oxford, memory strategies may use grouping or imagery to assist students in storing and retrieving information. Cognitive strategies may be used to summarize or reason deductively in order to help learners understand and produce new language through various means, while compensation strategies may include guessing or using synonyms to help learners use the language despite gaps in their L2 knowledge.

The indirect strategies include metacognitive, affective, and social strategies; these strategies "support and manage language learning without (in many instances) directly involving the target language" (R. L. Oxford, 1990, p. 135). Metacognitive strategies are those which allow learners to use their own cognition in order to coordinate learning processes and plan and evaluate their learning. Social strategies include those that help students learn through interaction with other learners, while affective strategies may help to regulate emotions, motivational levels, and attitudes towards the target language and learning. According to Oxford (1990), direct and indirect strategies work together, and all are applicable to all language skills.

Oxford's (1990) classification system, the Strategy Inventory for Language Learning (SILL), has received a great deal of attention in the past 27 years. In reviewing the SILL, Ko (2002) noted that, despite any shortcomings it may have, "its 'whole person' theoretical orientation towards L2 learning behaviors has the potential to expand the traditional limited conception of what happens when learning a new language" (p. 56). In this study, the SILL is used to examine the subjects' language learning strategy use.

The SILL has been used at all levels of education in Taiwan to examine students' learning strategy use. Tu (2014) investigated primary school students and found that they used metacognitive strategies most frequently and affective strategies the least, with an overall medium strategy use. Yeh (2013) examined junior high school students and found that they seldom used language learning strategies when learning English. When they did use them, they relied mostly on compensation strategies and used affective strategies the least.

As for senior high school, Huang (2014) examined the learning strategy preferences of normal and vocational high school students and found that both groups used predominantly compensation strategies but used metacognitive strategies the least. Moreover, students from normal high schools used language learning strategies more frequently than students from vocational schools. Finally, in a Taiwan university setting, Liu and Chang (2013) looked at the language learning strategy use of Taiwanese university freshmen and found that they relied mostly on compensation strategies and used social strategies the least.

\subsection{Motivation and Language Learning Strategies}

Studies linking motivation and language learning strategies have previously been employed in Asian educational contexts. Khamkhien (2010) looked at Thai and Vietnamese students' performance on the SILL as it related to motivation, gender, and experience in studying English. He found that motivation was the most significant factor affecting the choice of strategies. Lan and Oxford (2003) looked at the strategy use of elementary school students in Taiwan and found that their degree of liking English, an indicator of their motivation to learn, was the most influential factor affecting strategy use.

Studies linking motivation and strategy usage have also been done in other foreign language learning contexts. Okada, Oxford, and Abo (1999) conducted a study among college learners of Japanese and Spanish. Their findings were that learners of Japanese were not only more motivated but also used more strategies more often than the students learning Spanish. Moreover, the study revealed significant correlations between motivation and strategy use for both the Japanese learners $(r=.56, p<.002)$ and the Spanish learners $(r=.58, p$ $=.000$ ). In addition, MacIntyre and Noels (1996) tested 138 learners of either Spanish or Italian and found not 
only a connection between the motivation to learn and strategy use, but found that metacognitive strategies had the strongest correlation $(r=.57, p<.001)$ with motivation.

Oxford and Nyikos (1989), examining 1,200 students studying five different foreign languages also found that motivation was the most important factor affecting the choice and use of learning strategies. Similarly, Bonney, Cortina, Smith-Darden, and Fiori (2008) examined motivational variables and learning strategy usage among 694 high school students from 36 foreign language classrooms. They found that intrinsic motivation was strongly and significantly correlated with extracurricular activities $(r=.53, p<.001)$ while integrative motivation was significantly correlated with compensatory and cognitive learning strategies (both $r=.44, p$ $<.001)$ as well as extracurricular activities $(r=.43, p<.001)$. Bonney et al. concluded that intrinsic and integrative motivation could be serve as primary predictors of strategy use.

\subsection{High School Program}

Senior high schools in Taiwan are divided into normal high school and vocational schools. Whereas normal high schools offer science and liberal arts tracks, vocational high schools place more emphasis on practical or vocational skills, such as engineering, business, or agriculture ("Education in Taiwan," 2017). Comprehensive senior high schools offer both normal and vocational programs. Regardless of high school program, all students are directed toward the goal of taking the national university entrance exams to attend college. Jou and Wang (2013) noted that "university enrollments are now commonly filled by students who have gone to either vocational high school and [normal] high schools" (p. 364).

Moreover, Chen (2008) noted that educational opportunity inequalities in Taiwan are due to four reasons: (1) school factors, such as budget and equipment; (2) geographical factors, such as the urban or rural environment and regional conditions; (3) students' family background, such as social status and parents' educational levels; and (4) students' personal factors, such as gender, religion, and interests. Certainly, these factors may influence students in choosing one senior high school program over another. Weiner (2008) also pointed out that a learner's motivation is closely related to one's social motivation which is determined by one's environment. In other words, the learning environment and school influence may be strong factors in learners' motivational selves and learning strategy selection.

\subsection{Research Questions}

It is apparent that language learning strategy use and motivation are highly correlated and that either of these variables may vary by grade, proficiency, program, or perhaps by other outside variables. While much research has been done in the areas of both motivation and language learning strategy usage in educational contexts in Taiwan, some gaps still exist. No one has investigated university students' Ideal L2 Selves or Language Learning Strategy Use (LLSU) to determine any links between the variables or differences among the populations according to which high school program they attended or how long they have studied at university. This study seeks to fill that gap by examining the following research questions:

1. What factors comprise Taiwanese University English majors' Motivational Selves?

2. What learning strategies do Taiwanese University English majors use?

3. Are there any relationships or correlations between the factors in the Motivational Self System or SILL variables?

4. Do the Motivational Self System and SILL variables differ among these learners due to high school program or current year of study?

\section{Methodology}

This section examines the participants, instruments, and procedures for the study.

\subsection{Participants}

The participants for the current study are 96 Taiwanese university English majors (45 males, 51 females) ages $18-25(M=20.5)$. There are 26 freshmen, 27 sophomores, 21 juniors, and 22 seniors in the group. The majority of students $(N=60)$ have had a native English-speaking teacher before, but only two have studied abroad. The majority of subjects $(N=53)$ studied in vocational high schools, while 30 studied in normal high schools, and 13 studied in comprehensive programs. Despite having studied English primary school, they self-rated their proficiency levels, provided with descriptors for each level, as 10 beginners, 28 post-beginners, 27 lowerintermediate, 28 intermediate, and 3 upper intermediate. Slightly more than half $(N=49)$ had previously taken the TOEIC test and scored an average of 485 or an A2 level according to the Common European Framework of Reference.

\subsection{Instruments}

Two instruments plus a short questionnaire gathering subjects' background information and self-rated 
proficiency levels were used for this study. The first was a motivational selves questionnaire modified from Taguchi, Magid, and Papi (2009) and Ryan's (2009) Motivational Factors Questionnaire. Taguchi et al. created motivational selves questionnaires for Japanese, Iranian, and Chinese students. The current study employed their Chinese questionnaire, but it was converted to Traditional Chinese, the language was slightly modified for a Taiwanese audience by an experienced Chinese-English translator, and elements of Ryan's questionnaire, such as travel orientation and English learning anxiety were added. In addition, because Taguchi et al.'s "findings justify the replacement of integrativeness with the ideal L2 self' (p. 78), the three items measuring integrativeness were removed from the questionnaire. The questionnaire thus consisted of thirteen factors: (1) criterion measures, assessing the learners' intended efforts toward learning English; (2) ideal L2 self; (3) oughtto L2 self; (4) instrumentality-promotion, measuring personal goals of becoming successful; (5) instrumentalityprevention, measuring duties and obligations related to learning English; (6) family influence; (7) assimilation; (8) ethnocentrism; (9) anxiety; (10) cultural interest; (11) attitudes toward learning English; (12) attitudes toward the L2 community; and (13) travel orientation. The first part of the questionnaire was rated on a scale measuring from 1 (strongly disagree) to 6 (strongly agree). The second part of the questionnaire was rated on a scale from 1 (not at all) to 6 (very much). The overall reliability of this scale, as measured using Cronbach's alpha, was .916. The second instrument was the SILL questionnaire developed by Oxford (1990). More specifically, this study employed the validated Chinese version of the questionnaire used by Chen (2002). This questionnaire consists of 50 items in six language learning strategy categories: (1) memory strategies (items 1-9), (2) cognitive strategies (items 10-23), (3) compensation strategies (items 24-29), (4) metacognitive strategies (items 30-38), (5) affective strategies (items 39-44), and (6) social strategies (items 45-50). This questionnaire was rated on a scale from 1 (never or almost never true of me) to 5 (always or almost always true of me). Chen (2002) noted that her questionnaire was based on Liao's (2000) Chinese SILL which yielded a Cronbach alpha value of .96. The questionnaire was further modified by updating the language for a more modern age. For example, item 15 was modified to "I watch English language TV shows and movies or read/use English on the Internet." The scale used in this study achieved an overall reliability of .966.

\subsection{Research Procedure}

These questionnaires were served using Google Forms, an online survey website. Subjects were given access to the questionnaire through a link and given one hour to complete the questionnaires. Most students finished the questionnaires in less than 30 minutes. The data was then downloaded to Microsoft Excel, organized, and imported into SPSS 23 for data analysis. The procedures include Cronbach alpha for reliability, variable means, correlational analysis, and a MANOVA to examine the impact of high school program and length of study on the variables.

\section{Results}

The results are presented in several parts. First, the reliability measures of the variable factors will be examined. Then the correlations between the factors will be assessed. Finally, the overall factor means and MANOVA results will be presented. Table 1 presents the results of the Cronbach alpha reliability measures. All of the factors, with the exception of Travel Orientation reached acceptable levels of reliability. As such, Travel Orientation was not included in the MANOVA or Pearson's correlation procedures. 
Table 1. Factor reliability measures

\begin{tabular}{lc}
\hline Factor & Cronbach a \\
\hline MSS Criterion Measures & .858 \\
MSS Ideal L2 Self & .901 \\
MSS Ought-to Self & .810 \\
MSS Instrumentality-Promotion & .722 \\
MSS Instrumentality-Prevention & .822 \\
MSS Family Influence & .720 \\
MSS Assimilation & .730 \\
MSS Ethnocentrism & .729 \\
MSS Anxiety & .857 \\
MSS Cultural Interest & .782 \\
MSS Attitude toward Learning & .844 \\
MSS Attitude toward the L2 Community & .861 \\
MSS Travel Orientation & .568 \\
SILL Memory Strategies & .829 \\
SILL Cognitive Strategies & .912 \\
SILL Compensation Strategies & .730 \\
SILL Metacognitive Strategies & .920 \\
SILL Affective Strategies & .786 \\
SILL Social Strategies & .820 \\
\hline
\end{tabular}

Table 2 displays the results of the correlational analysis between the Motivational Self System and SILL factors. As can be seen, the Criterion measures, as well as Ideal L2 Self, Instrumentality-Promotion, Attitude toward Learning, and Attitude toward the L2 Community are significantly-and in some cases, stronglycorrelated with all SILL strategy types. Several other Motivational Self System factors, namely the Ought-to Self, Assimilation, Ethnocentrism, and Cultural Interest, are partially correlated with the SILL, mostly Memory, Cognitive, Affective, and Social strategies. Anxiety is the only MSS factor that is significantly negatively correlated with some SILL strategy types. Interestingly, Instrumentality-Prevention and Family Influence are the only two MSS factors which are not correlated with SILL strategy types at all.

Table 2. Correlations between MSS and SILL factors

\begin{tabular}{lllllll}
\hline MSS Factor & Mem. & Cog. & Comp. & Met. & Aff. & Soc. \\
\hline Criterion & $.476^{* * *}$ & $.511^{* * *}$ & $.219^{*}$ & $.675^{* * *}$ & $.422^{* * *}$ & $.480^{* * *}$ \\
Ideal L2 Self & $.461^{* * *}$ & $.520^{* * *}$ & $.504^{* * *}$ & $.577^{* * *}$ & $.428^{* * *}$ & $.511^{* * *}$ \\
Ought-to Self & $.351^{* * *}$ & $.330^{* *}$ & .124 & $.244^{*}$ & $.265^{* *}$ & $.367^{* * *}$ \\
Instrumentality-Promotion & $.458^{* * *}$ & $.479^{* * *}$ & $.369^{* * *}$ & $.458^{* * *}$ & $.368^{* * *}$ & $.533^{* * *}$ \\
Instrumentality-Prevention & .194 & .107 & .054 & -.078 & .100 & .147 \\
Family Influence & .188 & .138 & -.084 & .068 & .131 & .140 \\
Assimilation & $.277^{* *}$ & $.226^{*}$ & .145 & $.212^{*}$ & $.215^{*}$ & $.321^{* * *}$ \\
Ethnocentrism & $.271^{* *}$ & $.231^{*}$ & .122 & .109 & $.264^{* *}$ & .149 \\
Attitude toward Learning & $.499^{* * *}$ & $.564^{* * *}$ & $.352^{* * *}$ & $.657^{* * *}$ & $.460^{* * *}$ & $.533^{* * *}$ \\
Attitude toward L2 Comm. & $.456^{* * *}$ & $.529^{* * *}$ & $.397^{* * *}$ & $.596^{* * *}$ & $.437^{* * *}$ & $.544^{* * *}$ \\
Anxiety & -.149 & $-.406^{* * *}$ & -.172 & $-.426^{* * *}$ & -.153 & $-.294^{* *}$ \\
Cultural Interest & $.268^{* *}$ & $.267^{* *}$ & .169 & .195 & $.256^{*}$ & $.332^{* * *}$ \\
\hline
\end{tabular}

Note. $*=\mathrm{p}<.05, * *=\mathrm{p}<.01, * * *=\mathrm{p}<.001$

Tables 3 and 4 display the overall means for the factors in both the Motivational Self System and the SILL, respectively, as well as the means for students according to high school program. 
Table 3. Overall means for motivational self system according to high school program

\begin{tabular}{lllll}
\hline Factor & Norm. & Comp. & Voc. & Mean \\
\hline MSS Criterion & 4.56 & 4.00 & 4.34 & 4.36 \\
MSS Ideal L2 Self & 4.82 & 4.45 & 4.49 & 4.59 \\
MSS Ought-to Self & 3.12 & 3.16 & 3.27 & 3.21 \\
MSS Instrumentality-Promotion & 4.59 & 4.51 & 4.50 & 4.53 \\
MSS Instrumentality-Prevention & 3.13 & 3.29 & 3.39 & 3.29 \\
MSS Family Influence & 3.40 & 3.14 & 3.31 & 3.31 \\
MSS Assimilation & 2.68 & 3.00 & 2.92 & 2.86 \\
MSS Ethnocentrism & 2.99 & 2.62 & 3.09 & 3.00 \\
MSS Anxiety & 3.29 & 3.88 & 3.83 & 3.67 \\
MSS Attitude toward Learning & 4.35 & 3.94 & 4.33 & 4.28 \\
MSS Attitude toward L2 Community & 4.97 & 4.81 & 4.73 & 4.81 \\
MSS Cultural Interest & 5.08 & 4.85 & 4.96 & 4.98 \\
\hline Table 4. Overall means for SILL according to high school program & & & Mean \\
\hline Factor & Norm. & Comp. & Voc. & 2.98 \\
\hline SILL Memory Strategies & 3.00 & 2.80 & 3.01 & 3.13 \\
SILL Cognitive Strategies & 3.26 & 3.01 & 3.09 & 3.14 \\
SILL Compensation Strategies & 3.14 & 3.21 & 3.12 & 3.26 \\
SILL Metacognitive Strategies & 3.36 & 3.06 & 3.25 & 2.95 \\
SILL Affective Strategies & 2.96 & 2.83 & 2.97 & 3.12 \\
SILL Social Strategies & 3.18 & 2.87 & 3.15 & \\
\hline
\end{tabular}

Tables 5 and 6 display the means for the factors in the motivational self system and the SILL, respectively, according to current year of study. Further analysis by MANOVA found no significant difference among the students according to current year of study, $F(54,224)=1.258, p=.127$, Wilk's $\Lambda=.454$, or high school program, $F(36,152)=.925, p=.595$, Wilk's $\Lambda=.673$. That is to say, neither high school program nor current year of study affected students' Motivational Self Systems or learning strategy usage.

Table 5. Means for motivational self system according to current year of study

\begin{tabular}{lllll}
\hline Factor & 1 & 2 & 3 & 4 \\
\hline MSS Criterion & 4.43 & 4.40 & 4.43 & 4.18 \\
MSS Ideal L2 Self & 4.52 & 4.79 & 4.35 & 4.66 \\
MSS Ought-to Self & 3.19 & 2.95 & 3.25 & 3.51 \\
MSS Instrumentality-Promotion & 4.40 & 4.48 & 4.67 & 4.60 \\
MSS Instrumentality-Prevention & 3.13 & 3.00 & 3.31 & 3.84 \\
MSS Family Influence & 3.24 & 3.02 & 3.52 & 3.57 \\
MSS Assimilation & 2.62 & 2.99 & 2.91 & 2.93 \\
MSS Ethnocentrism & 2.86 & 2.93 & 3.02 & 3.22 \\
MSS Anxiety & 3.55 & 3.69 & 3.81 & 3.65 \\
MSS Attitude toward Learning & 4.31 & 4.36 & 4.13 & 4.30 \\
MSS Attitude toward L2 Community & 4.62 & 4.89 & 4.79 & 4.98 \\
MSS Cultural Interest & 4.73 & 4.86 & 5.21 & 5.20 \\
\hline
\end{tabular}

Table 6. means for SILL factors according to current year of study

\begin{tabular}{lllll}
\hline Factor & 1 & 2 & 3 & 4 \\
\hline SILL Memory Strategies & 2.83 & 3.00 & 3.00 & 3.12 \\
SILL Cognitive Strategies & 3.02 & 3.12 & 3.13 & 3.30 \\
SILL Compensation Strategies & 2.87 & 3.20 & 3.26 & 3.27 \\
SILL Metacognitive Strategies & 3.15 & 3.42 & 3.22 & 3.23 \\
SILL Affective Strategies & 2.71 & 3.03 & 2.97 & 3.12 \\
SILL Social Strategies & 2.96 & 3.06 & 3.20 & 3.31 \\
\hline
\end{tabular}

\section{Discussion}

The first research question asked what factors comprise Taiwanese university English majors' Motivational Self Systems. The results showed that the questionnaire used by Taguchi, Magid, and Papi (2009), with the exception of Travel Orientation, was valid and all factors achieved reliable measures.

That these subjects did not have a Travel Orientation may be due to the fact that so few of them-only two- - had ever studied abroad before. Since the subjects are located in central Taiwan, they may not have that 
much contact with English native speakers or a more globalized world, such as one might encounter in larger cities like Taipei. As such, while they may appreciate the L2 culture and community and have visions of the Ideal and Ought-to selves, they may not have much desire to leave Taiwan or travel abroad. Another factor could be their proficiency in English; they may feel that their English is not good enough for traveling abroad and interacting with others. If these students had higher proficiency or were located in a larger city, they may have had a Travel Orientation and more desire to travel, study, or live abroad.

The second research question asked what strategy types are used by Taiwanese university English majors. The results showed that overall, Taiwanese university English majors made only medium use of all six types of strategies. They used metacognitive strategies the most and affective strategies the least. Interestingly, these results echo those of Tu (2014), who studied primary school students, although Yeh's (2013) subjects also used affective strategies the least. This may be because the subjects in this study come mostly from vocational high school programs and have relatively low proficiency overall.

These results also differ from those of Liu and Chang (2013), who found that the 163 university freshmen in their study used compensation strategies the most and social strategies the least. However, the subjects in Liu and Chang's study came from different academic departments and were enrolled in a university-wide required English course. The subjects in the current study are English majors, so perhaps their more frequent contact with the language allows them to employ more metacognitive strategies and think about their learning.

The third research question asked whether any relationships exist between the factors in the MSS and the SILL. As the results show, many correlations exist between the factors. In particular, the Criterion measures as well as the Ideal L2 Self, Instrumentality-Promotion, and both Attitude toward Learning and Attitude toward the L2 Community are all strongly and significantly correlated with all strategy types. All but InstrumentalityPromotion are most strongly correlated with metacognitive strategies, which is what one would expect to see from motivated students. Instrumentality-Promotion is most strongly associated with Social Strategies, which may show that Taiwanese depend on peers and friends (Huang, 2015) to achieve higher proficiency in English which in turn may lead to a better job or making more money.

Other factors, namely Ought-to Self, Assimilation, Ethnocentrism, and Cultural Interest were correlated with certain strategies; Ethnocentrism is most strongly correlated with Memory Strategies, but the other three are most strongly correlated with Social Strategies. The reasons for this remain unclear. Because ethnocentrism can lead to a lack of communication (Gudykunst, 1997) and includes beliefs and attitudes that one's own culture is superior to others (Neuliep, Chaudoir, \& McCroskey, 2001), it may be that this factor is more strongly correlated with memory strategies, such as rote memorization, which are traditional learning styles in Chinese classrooms. However, Ought-to Self, Assimilation, and Cultural Interest may rely more on social strategies because, again, these students are located in central Taiwan. They may get a lot of their views on foreign cultures from their friends rather than through personal experience.

Interestingly, Anxiety was the only factor that was negatively correlated with Cognitive, Metacognitive, and Social strategies. That is, as anxiety levels rise, students use fewer of these types of strategies, perhaps once again resorting to Memorization or Compensation strategies, which most Asian learners tend to use (Chu, Huang, Shih, \& Tsai, 2012; Huang, 2014; Liu \& Chang, 2013; Yeh, 2013). Moreover, Instrumentality-Prevention and Family Influence were the only two factors not associated with any strategies. This means that family influence does not have an effect on strategy choice and that while students may have a medium or high level of Instrumentality-Prevention, they do not use learning strategies in order to avoid negative outcomes.

The final research question sought to examine whether there were any differences among the MSS and SILL variables due to the students' high school programs or current year of study. The results of MANOVAs showed that no significant differences existed. That is to say, neither high school program nor current year of study affected students' motivational selves or learning strategy usage. It appears that any effect that may have been present from vocational, comprehensive, or normal high schools does not last through to university. Similarly, students do not significantly change their motivational selves or learning strategy choice as they progress in their studies and get closer to graduating. This may be because these students have relatively low proficiency and do not receive explicit instruction in learning strategies; thus, they rely on the same learning strategies throughout their university studies. Moreover, since they are located in central Taiwan and do not have much contact with a more globalized world, they may not have the chance to develop their motivational selves as much as subjects who live in Taipei or Kaohsiung might. Additionally, there may be other factors at play; for example, perhaps the location of their high school or home - in urban or rural environments - is a predicting factor, or perhaps their parents' educational level may influence their strategy usage and motivational selves. More research is needed to examine these factors.

\section{Conclusion}

This study has examined the motivational selves and learning strategy usage of Taiwanese university English majors. The results have shown the form of Taiwanese students' motivational selves and their learning strategy 
preferences; additionally, the results have supported previous findings that found correlations and connections between motivation and learning strategy choice. The current study also showed that there were no differences among the students in these variables according to current year of study or previous high school program. Based on these results, there are several suggestions for future research and limitations of the current research.

First, future research should continue to explore Taiwanese students' motivational selves and learning strategy preferences. That these two variables are connected is shown throughout the previous literature and in this study. Being able to see what strategies students are using, which ones they are lacking, and helping them develop their motivational selves is of the utmost importance to teachers and practitioners. However, future research may look at using different questionnaires. The SILL, while validated and dependable, does not distinguish between language learning strategies and language use strategies (Cohen, 2011). As such, perhaps a more updated strategy questionnaire is needed to accurately measure Taiwanese students' language learning strategies (Lai, 2009). The current study was also limited in that it only examined subjects from one school. Future research should expand the subject selection to other schools and areas. Factors affecting students' motivational selves and learning strategy choice may be the location of the school or the level of the universityprivate, normal, or national. Future research could also include some qualitative post-hoc interviews to more deeply examine students' attitudes and strategy choices. Questionnaires may be able to answer the what of motivational selves and strategy choice, but they cannot answer the why. Implementing a mixed-methods approach to this research topic may prove beneficial to both teachers and learners in the future.

\section{References}

Bonney, C. R., Cortina, K. S., Smith-Darden, J. P., \& Fiori, K. L. (2008). Understanding strategies in foreign language learning: Are integrative and intrinsic motives distinct predictors? Learning and Individual Differences, 18(1), 1-10. https://doi.org/10.1016/j.lindif.2007.11.005

Chamot, A. U., Barnhardt, S., El-Dinary, P., \& Robbins, J. (1996). Methods for teaching learner strategies in the foreign language classroom. In R. L. Oxford (Ed.), Language learning strategies around the world: Crosscultural perspectives (pp. 175-187). Honolulu, HA: Second Language Teaching \& Curriculum Center, University of Hawai'i at Mānoa.

Chen, I.-J. (2002). Language learning strategies used by high and low English proficiency students in a technology college (Master's thesis). National Changhua University of Education, Changhua, Taiwan. Retrieved from http://handle.ncl.edu.tw/11296/ndltd/24309260070732862620

Chen, S. (2008). 談父親角色與影響其參與的因素. 教師之友, 49(1), 60-70.

Cheng, C.-T. (2015). Differences of multiple intelligences and language learning strategies between senior high school students of different academic groups (Master's thesis). National Changhua University of Education, Changhua, Taiwan. Retrieved from http://handle.ncl.edu.tw/11296/ndltd/05756690280866096521

Chu, H.-L. (2014). The investigation of international posture and L2 self among Taiwanese college students (Master's thesis). Ming Chuan University, Taipei, Taiwan. Retrieved from http://handle.ncl.edu.tw/11296/ndltd/34136697274669092684

Chu, Y.-W., Huang, B.-S., Shih, M.-P., \& Tsai, C.-H. (2012). A look at EFL technical students' use of learning strategies in Taiwan. World Journal of Education, 2(3), 16-24. https://doi.org/10.5430/wje.v2n3p16

Cohen, A. D. (2010). Focus on the language learner: Styles, strategies and motivation. In N. Schmitt (Ed.), An introduction to applied linguistics (2nd ed., pp. 161-178). London, UK: Hodder Education.

Cohen, A. D. (2011). Strategies in learning and using a second language (2nd ed.). New York, NY: Pearson/Longman.

Cohen, A. D., \& Macaro, E. (Eds.). (2007). Language learner strategies: Thirty years of research and practice. Oxford, UK: Oxford University Press.

Dörnyei, Z. (1990). Conceptualizing motivation in foreign-language learning. Language Learning, 40(1), 45-78. https://doi.org/10.1111/j.1467-1770.1990.tb00954.x

Dörnyei, Z. (2005). The psychology of the language learner: Individual differences in second language acquisition. Mahwah, NJ: Lawrence Erlbaum Associates.

Dörnyei, Z. (2009). The L2 motivational self system. In Z. Dörnyei \& E. Ushioda (Eds.), Motivation, language identity and the L2 self (pp. 9-42). Bristol, UK: Multilingual Matters.

Dörnyei, Z., \& Ushioda, E. (Eds.). (2009). Motivation, language identity and the L2 self. Bristol, UK: Multilingual Matters.

Dörnyei, Z., \& Ushioda, E. (2011). Teaching and researching motivation (2nd ed.). New York, NY: Longman/Pearson.

Education in Taiwan. (n.d.) In Wikipedia. Retrieved November 16, 2017, from https://en.wikipedia.org/wiki/Education_in_Taiwan

Ehrman, M., \& Oxford, R. (1990). Adult language learning styles and strategies in an intensive training setting. The Modern Language Journal, 74(3), 311-327. https://doi.org/10.1111/j.1540-4781.1990.tb01069.x 
Gardner, R. C. (1985). Social psychology and second language learning: The role of attitudes and motivation. London, UK: Edward Arnold.

Gudykunst, W. B. (1997). Toward a theory of effective interpersonal and intergroup communication. In R. L. Wiseman \& J. Koester (Eds.), Intercultural communication competence (pp. 33-71). Newbury Park, CA: Sage Publications.

Huang, T.-F. (2014). Learning strategy use of high school students in central Taiwan (Master's thesis). Da-Yeh University, Changhua, Taiwan. $\quad$ Retrieved from http://handle.ncl.edu.tw/11296/ndltd/98017207854038905418

Huang, S. C. (2015). Significant others in influencing Chinese EFL students' learning strategy use: From a sociocultural perspective. In W. M. Chan, S. K. Bhatt, M. Nagani, \& I. Walker (Eds.), Culture and foreign language education: Insights from research and implications for the practice (pp. 245-261). Boston, MA: De Gruyter Mouton.

Jou, M., \& Wang, J. (2013). Observations of achievement and motivation in using cloud computing driven CAD: Comparison of college students with high school and vocational high school backgrounds. Computers in Human Behavior, 29(2), 364-369. https://doi.org/10.1016/j.chb.2012.08.001

Khamkhien, A. (2010). Factors affecting language learning strategy reported usage by Thai and Vietnamese EFL learners. Electronic Journal of Foreign Language Teaching, 7(1), 66-85. Retrieved from http://eflt.nus.edu.sg/v7n12010/khamkhien.pdf

Ko, Y. (2002). Perceptual style preferences and their relationship to English achievement and learning strategies of junior high EFL learners in Taiwan (Master's thesis). National Kaohsiung Normal University, Kaohsiung, Taiwan. Retrieved from http://handle.ncl.edu.tw/11296/ndltd/22055232371046002273

Ko, Y. H. (2015). A self system perspective on early adolescents' English learning motivation: Differences in urban and rural areas and the intervention program (Master's thesis). National Tsing Hua University, Hsinchu, Taiwan. Retrieved from http://handle.ncl.edu.tw/11296/ndltd/71233250699725863590

Lai, Y. C. (2009). Language learning strategy use and English proficiency of university freshmen in Taiwan. TESOL Quarterly, 43(2), 255-280. https://doi.org/10.1002/j.1545-7249.2009.tb00167.x

Lan, R., \& Oxford, R. L. (2003). Language learning strategy profiles of elementary school students in Taiwan. International Review of Applied Linguistics in Language Teaching, 41(4). https://doi.org/10.1515/iral.2003.016

Liao, Y. (2000). A study of Taiwanese junior high school students' EFL learning motivation and learning strategies (Master's thesis). National Changhua University of Education, Changhua, Taiwan. Retrieved from http://handle.ncl.edu.tw/11296/ndltd/92434101116402537502

Liu, H., \& Chang, C. (2013). A study on language learning strategy use and its relation to academic self-concept: The case of EFL students in Taiwan. Journal of Language Teaching and Research, 4(2), 260-268. https://doi.org/10.4304/jltr.4.2.260-268

Lo, H. Y. (2015). Parental influence on Taiwanese adolescents' English learning motivation, L2 selves, and international posture (Master's thesis). National Tsing Hua University, Hsinchu, Taiwan. Retrieved from http://handle.ncl.edu.tw/11296/ndltd/32214896151085898128

MacIntyre, P. D., \& Noels, K. A. (1996). Using social-psychological variables to predict the use of language learning strategies. Foreign Language Annals, 29(3), 373-386. https://doi.org/10.1111/j.19449720.1996.tb01249.x

Naiman, N., Fröhlich, M., Stern, H. H., \& Todesco, A. (1996). The good language learner. Clevedon, UK: Multilingual Matters.

Neuliep, J. W., Chaudoir, M., \& McCroskey, J. C. (2001). A cross - cultural comparison of ethnocentrism among Japanese and United States college students. Communication Research Reports, 18(2), 137-146. https://doi.org/10.1080/08824090109384791

Noels, K. A., Pelletier, L. G., Clément, R., \& Vallerand, R. J. (2000). Why are you learning a second language? Motivational orientations and self-determination theory. Language Learning, 50(1), 57-85. https://doi.org/10.1111/0023-8333.00111

Okada, M., Oxford, R. L., \& Abo, S. (1999). Not all alike: Motivation and learning strategies among students of Japanese and Spanish in an exploratory study. In R. L. Oxford (Ed.), Language learning motivation: Pathways to the new century. Honolulu, Hawaii: Second Language Teaching \& Curriculum Center.

O’Malley, J. M., \& Chamot, A. U. (1990). Learning strategies in second language acquisition. Cambridge, UK: Cambridge University Press.

Oxford, R. L. (1990). Language learning strategies: What every teacher should know. Boston, MA: Heinle \& Heinle.

Oxford, R. L. (2017). Teaching and researching language learning strategies: Self-regulation in context (2nd ed.). New York, NY: Routledge.

Oxford, R., \& Nyikos, M. (1989). Variables affecting choice of language learning strategies by university 
students. The Modern Language Journal, 73(3), 291-300. https://doi.org/10.1111/j.15404781.1989.tb06367.x

Rubin, J. (1975). What the "good language learner" can teach us. TESOL Quarterly, 9(1), 41-51. https://doi.org/10.2307/3586011

Ryan, S. (2009). Self and identity in L2 motivation in Japan: The ideal L2 self and Japanese learners of English. In Z. Dörnyei \& E. Ushioda (Eds.), Motivation, language identity and the L2 self (pp. 120-143). Buffalo, NY: Multilingual Matters.

Schunk, D. H., Meece, J. L., \& Pintrich, P. R. (2014). Motivation in education: Theory, research, and applications (4th ed.). Boston, MA: Pearson.

Taguchi, T., Magid, M., \& Papi, M. (2009). The L2 motivational self system among Japanese, Chinese and Iranian learners of English: A comparative study. In Z. Dörnyei \& E. Ushioda (Eds.), Motivation, language identity and the L2 self (pp. 66-97). Bristol, UK: Multilingual Matters.

Tu, J. (2014). A study of language learning strategies used by primary school students in Kaohsiung (Master's thesis). National Kaohsiung Normal University, Kaohsiung, Taiwan. Retrieved from http://handle.ncl.edu.tw/11296/ndltd/07256024662573644274

Ushioda, E. (2002). Language learning at university: Exploring the role of motivational thinking. In Z. Dörnyei \& R. Schmidt (Eds.), Motivation and second language acquisition (pp. 93-125). Mānoa, HA: University of Hawaii Press.

Warden, C. A., \& Lin, H. J. (2000). Existence of integrative motivation in an Asian EFL setting. Foreign Language Annals, 33(5), 535-545. https://doi.org/10.1111/j.1944-9720.2000.tb01997.x

Weiner, B. (1994). Integrating social and personal theories of achievement striving. Review of Educational Research, 64(4), 557-573. https://doi.org/10.3102/00346543064004557

Yashima, T. (2002). Willingness to communicate in a second language: The Japanese EFL context. The Modern Language Journal, 86(1), 54-66. https://doi.org/10.1111/1540-4781.00136

Yeh, C.-H. (2013). EFL learning strategy use of junior high school students (Master's thesis). National Changhua University of Education, Changhua, Taiwan. Retrieved from http://handle.ncl.edu.tw/11296/ndltd/86622520351743316423

Zhan H., \& Xue C. (2008, January 23). Exploring M-shaped Society and Policy Implications for Taiwan. Retrieved January 17, 2019, from https://www.npf.org.tw/2/3868 